\title{
ASYMPTOTIC FORMULAE FOR THE ACOUSTIC SELF-IMPEDANCE OF SIMPLY-SUPPORTED AND SIMPLY SUPPORTED-CLAMPED ANNULAR PLATES
}

\begin{abstract}
This study focuses on the sound radiation of a vibrating flat annular plate. The rigorous theoretical considerations deal with some time-harmonic and axisymmetric vibrations. Three different boundary configurations are considered, i.e. one of the plate's edges is simply supported and the other one is clamped or also is simply supported. The active and reactive self-impedance of the system are presented in their Hankel's representations, valid within the whole frequency spectrum. The expressions obtained are transformed to their elementary forms, valid for the high frequencies. Low fluid loading and low internal friction of the plate are assumed. The obtained results are illustrated with sample plots in the domain of acoustic wavenumber. Elementary formulae presented can be useful for further theoretical analysis of the total sound power radiated by an excited flat plate in an acoustic fluid as well as for efficient engineering computations.
\end{abstract}

Keywords: active and reactive self-impedance, sound radiation for the high frequencies, annular flat plate in a rigid baffle

\section{WYZNACZANIE AKUSTYCZNEJ IMPEDANCJI WŁASNEJ PŁASKICH PŁYT PIERŚCIENIOWYCH O RÓŻNYCH KONFIGURACJACH BRZEGOWYCH Z ZASTOSOWANIEM RÓWNAŃ ASYMPTOTYCZNYCH}

W pracy podjęto zagadnienie promieniowania dźwięku przez drgajaca płaska ptyte pierścieniowa. Ścisłe rozważania teoretyczne dotyczq osiowosymetrycznych drgań harmonicznych. Rozpatrzono trzy różne konfiguracje brzegowe, tj. dla jednej krawędzi ptyty swobodnie podpartej, a drugiej utwierdzonej lub swobodnie podpartej. Czynnq i biernq impedancje wtasnq uktadu drgajqcego przedstawiono w reprezentacji Hankela, stusznej w catym spektrum czestości. Wyrażenia te zostaty przeksztatcone do ich elementarnych postaci, słusznych dla wysokich czestości. Zatożono, że wpływ powietrza na drgania płyty oraz ttumienie wewnętrzne sq znikome. Otrzymane wyniki zilustrowano wybranymi wykresami w funkcji liczby falowej. Przedstawione wzory elementarne moga być przydatne do dalszej analizy teoretycznej catkowitej mocy promieniowania dźwięku przez ptaska ptyte pobudzonq do drgań z uwzglednieniem wptywu ośrodka, jak również do szybkich obliczeń inżynierskich.

Stowa kluczowe: czynna i bierna impedancja wtasna, promieniowanie dźwięku dla wysokich czestości, płaskie ptyty pierścieniowe w sztywnej odgrodzie

\section{INTRODUCTION}

The problems of acoustic waves generation and propagation by vibrating surfaces of finite geometric sizes have been quite intensively investigated both, theoretically and experimentally, for several years now. The obtained results make it possible to identify and model the acoustic fields generated by numerous devices used in the petroleum industry and other industrial branches, in communication, and in several common devices such as computer disks. The purely theoretical investigations usually require a number of simplifying assumptions are made for theoretical considerations on the sound field generation of some vibrating flat plates. Nevertheless, some theoretical results known from the literature make possible some effective experimental investigations and measurements. Additionally, any theoretical results provide some rough approximations for some energy magnitudes describing the generated sound field, if the investigated acoustic system satisfies the assumptions made. Therefore, the analytical solutions for the sound radiation problems have been found for the simplest piston radiators only. However, it is difficult or impossible to obtain the elementary expressions for some complex acoustic systems. Therefore, few papers present some approximate methods to describe the sound radiation by some flat plates of finite geometric dimensions.

Czarnecki, Engel and Panuszka (1981) applied the method of equivalent area of a clamped circular plate to roughly estimate the sound radiation efficiency obtaining some highly effective elementary formulae. Lee and Singh (1994) applied the Rayleigh-Ritz method to derive expressions for the radiation efficiency of a computer disk. The authors focused particularly on the influence of disk rotation on the acoustic field generated. Rdzanek and Engel (2000) presented asymptotic formulae of the self-impedance of a clamped annular plate. Rdzanek (2003) analyzed the sound radiation of clamped-free and free-clamped annular plates embedded in the infinite rigid baffle using the Hankel transform obtaining the asymptotic formulae for the acoustic self-impedance coefficients. Lee and Singh (2005) examined the influence of thickness of an annular plate on sound radiation. The authors used both analytical and semi-analytical methods to solve this problem. Anderson and Bratos-Anderson (2005) studied the sound radiation efficiency of orthotropic rectangular plates with dimensions greater than the structural wavelength. The numerical results were compared to the experimental data. The hyper-matrices of acoustic impedance were used to estimate the complex acoustic power

\footnotetext{
* University of Rzeszów, Department of Mechatronics and Control Science, Faculty of Mathematics and Natural Sciences, Rzeszów, Poland,
} wprdzank@ur.edu.pl 
by Arenas and Albaracín (2007). This method applies a number of equivalent pistons instead of the vibrating surface, which, in consequence, gives a considerable reducing in the computation time. Zawieska (2007) analysed the active control of noise emitted by the high power electric transformers. The front panel of the transformer enclosure was considered to be an excited simply supported rectangular plate. It was modeled experimentally using an array of loudspeakers yielding a satisfactory accuaracy. Mellow and Kärkkäinen (2007) presented a new rigorous method for calculating the far field sound radiation from a shallow spherical shell in an acoustic medium. The eigenfunction expansion was used and the King integrals were solved analytically. Rdzanek and Rdzanek (2007) considered the acoustic impedance coefficients of an elastically supported annular plate for axisymmetric vibrations. As a result, the asymptotic formulas were obtained. Leniowska (2008) presented the effect of viscous damping, structural damping and fluid loading on the active vibration control of a circular plate of axisymmetric vibrations. For this purpose, the linear state model was applied together with the orthogonal series method. Kozień and Wiciak (2010) analyzed the acoustic pressure output of an excited squared simply-supported plate using the finite element method. The energy relationships were used to develop the governing equations of forced asymmetric vibrations of sandwich panels by Zhou and Crocker (2010). The results obtained were used to determine the sound transmission loss of such panels. The same method was used by Arenas, Ramis, and Alba (2010) to estimate the sound field of an elliptically shaped transducer in an infinite baffle. Kuo, Shiah, and Huang (2011) applied the modal analysis to determine the near-field and far-field sound pressure of the vibrator membrane of an actual portable loudspeaker. The glued edge of the membrane was considered to be elastically supported. Brański and Szela (2011) examined the effectiveness of the active vibration reduction of a triangular plate is evaluated using the piezo ceramic actuators. Mazur and Pawełczyk (2013) used nonlinear control filters such as Artificial Neural Networks or Volterra filters for active noise control of vibrating plates. The control system was verified experimentally. Wrona and Pawełczyk (2013) analyzed the influence of actuator placement on the controllability of a vibrating fully clamped rectangular plate for active noise-vibration control using a memetic algorithm. The results were validated experimentally. Szemela (2013) developed rigorously the asymptotic formulas of the acoustic impedance modal coefficients of a clamped circular plate located at the boundary of the three-wall corner. Oberst, Lai, and Marburg (2013) presented guidelines for the numerical vibration and the acoustic analysis of brake squeal using models of simplified brake systems with the friction contact. The annular plate used in the break system was considered to be thick.

So far, the asymptotic formulae of the acoustic selfimpedance coefficients of an annular plate with specific boundary configurations can be obtained in Rdzanek and Rdzanek (2007). Nevertheless, the detailed analysis for an annular plate was not presented so far, where one edge of the plate is simply supported and the other is clamped or is simply supported.
Therefore, the main aim of this study is to fill this literature gap and to provide the appropriate results useful for engineering computations valid for frequencies higher than the successive eigenfrequencies of the plates.

\section{ANALYSIS ASSUMPTIONS}

A flat annular plate is embedded in a flat rigid baffle. The plate performs some time-harmonic and axisymmetric vibrations of a small amplitude. The plate's vibrations are the source of some acoustic waves radiated into the hemisphere above the plate. Low fluid loading and low internal friction of the plate are assumed. The linear model of the plate by Kirchhoff-Love is used.

Three different boundary configurations of the plate are considered: (a) both edges of the plate are simply supported, (b) the internal edge is clamped and the external one is simply supported, (c) the internal edge is simply supported and the external one is clamped. Those three configurations are further referred to as: ss, cs and sc, respectively. The $n$-th mode shape of the plate is expected as (cf. McLachlan (1955) and Leissa (1969))

$$
\begin{array}{r}
W_{n}(r)=A_{n}\left[J_{0}\left(k_{n} r\right)+B_{n} I_{0}\left(k_{n} r\right)-C_{n} N_{0}\left(k_{n} r\right)\right. \\
\left.-D_{n} K_{0}\left(k_{n} r\right)\right],
\end{array}
$$

where $r \in[a, b]$ is the radial variable in polar coordinates, $a$ and $b$ are the internal and external radii of the plate, respectively. The clamped edge satisfies the following boundary conditions:

$$
W_{n}\left(r_{c}\right)=0,\left.\quad \frac{d}{d r} W_{n}(r)\right|_{r=r_{c}}=0,
$$

where $r_{c} \in\{a, b\}$ is the radius of the corresponding edge, whereas, the simply supported edge satisfies some other boundary conditions, i.e.

$$
W_{n}\left(r_{s}\right)=0,\left.\quad\left(\frac{d^{2}}{d r^{2}}+\frac{v}{r} \frac{d}{d r}\right) W_{n}(r)\right|_{r=r_{s}}=0,
$$

where $r_{s} \in\{a, b\}$ is the radius of the simply supported edge, $v$ is the Poisson's ratio.

It is not necessary to find the values of constants $A_{n}, B_{n}$ and $D_{n}$ to derive some energy magnitudes characterizing the sound radiation of an annular plate, therefore they are not presented herein. In the analysis presented in this paper the following convention is respected: if the magnitude is valid for one of the three boundary configurations, the subscript of the magnitude contains the corresponding denotation, i.e. ss, cs or sc, respectively. Several magnitudes valid for a clamped annular plate quoted from Rdzanek and Engel (2000) have been used as denotations in this paper, their subscript contains the letters cc.

After some mathematical manipulations it was found from equations (1)-(3) that the value of constant together with the frequency eqauation of the plate, can be formulated as 


$$
\begin{aligned}
C_{n, s s}= & \frac{s S\left(s x_{n}\right)-S\left(x_{n}\right)-2 \lambda_{n}\left[s^{2} J_{0}\left(s x_{n}\right) I_{0}\left(s x_{n}\right)-J_{0}\left(x_{n}\right) I_{0}\left(x_{n}\right)\right]}{s T\left(s x_{n}\right)-T\left(x_{n}\right)-2 \lambda_{n}\left[s^{2} N_{0}\left(s x_{n}\right) I_{0}\left(s x_{n}\right)-N_{0}\left(x_{n}\right) I_{0}\left(x_{n}\right)\right]} \\
= & \frac{s N\left(s x_{n}\right)-N\left(x_{n}\right)-2 \lambda_{n}\left[s^{2} J_{0}\left(s x_{n}\right) K_{0}\left(s x_{n}\right)-J_{0}\left(x_{n}\right) K_{0}\left(x_{n}\right)\right]}{s R\left(s x_{n}\right)-R\left(x_{n}\right)-2 \lambda_{n}\left[s^{2} N_{0}\left(s x_{n}\right) K_{0}\left(s x_{n}\right)-N_{0}\left(x_{n}\right) K_{0}\left(x_{n}\right)\right]}, \\
C_{n, c s}= & \frac{s S\left(s x_{n}\right)-S\left(x_{n}\right)-2 \lambda_{n} s^{2} J_{0}\left(s x_{n}\right) I_{0}\left(s x_{n}\right)}{s T\left(s x_{n}\right)-T\left(x_{n}\right)-2 \lambda_{n} s^{2} N_{0}\left(s x_{n}\right) I_{0}\left(s x_{n}\right)}=\frac{s N\left(s x_{n}\right)-N\left(x_{n}\right)-2 \lambda_{n} s^{2} J_{0}\left(s x_{n}\right) K_{0}\left(s x_{n}\right)}{s R\left(s x_{n}\right)-R\left(x_{n}\right)-2 \lambda_{n} s^{2} N_{0}\left(s x_{n}\right) K_{0}\left(s x_{n}\right)}, \\
C_{n, s c}= & \frac{s S\left(s x_{n}\right)-S\left(x_{n}\right)+2 \lambda_{n} J_{0}\left(x_{n}\right) I_{0}\left(x_{n}\right)}{s T\left(s x_{n}\right)-T\left(x_{n}\right)+2 \lambda_{n} N_{0}\left(x_{n}\right) I_{0}\left(x_{n}\right)}=\frac{s N\left(s x_{n}\right)-N\left(x_{n}\right)+2 \lambda_{n} J_{0}\left(x_{n}\right) K_{0}\left(x_{n}\right)}{s R\left(s x_{n}\right)-R\left(x_{n}\right)+2 \lambda_{n} N_{0}\left(x_{n}\right) K_{0}\left(x_{n}\right)},
\end{aligned}
$$

where $\lambda_{n}=x_{n}(1-v), x_{n}=k_{n} a$ denotes successive eigenfrequencies of the plate, $s=b / a$ is the geometric parameter of the plate, and

$$
\begin{aligned}
& S(x)=J_{1}(x) I_{0}(x)+J_{0}(x) I_{1}(x), \\
& T(x)=N_{1}(x) I_{0}(x)+N_{0}(x) I_{1}(x), \\
& N(x)=J_{1}(x) K_{0}(x)-J_{0}(x) K_{1}(x), \\
& R(x)=N_{1}(x) K_{0}(x)-N_{0}(x) K_{1}(x) .
\end{aligned}
$$

\section{INTEGRAL FORMULATIONS}

The Hankel's representation of the normalized complex self-impedance can be formulated as (cf. Rdzanek and Engel 2000)

$$
\Pi_{n}=\Pi_{a n}-i \Pi_{r n}=4 \delta_{n}^{4} q_{n} \int_{0}^{\infty} \psi_{n}^{2}(x) \frac{x d x}{\sqrt{1-x^{2}}},
$$

where $\Pi_{a n}$ and $\Pi_{r n}$ denote the active and reactive selfimpedance, respectively, $\delta_{n}=k_{n} / k$,

$$
\begin{aligned}
q_{n, s s}^{-1}= & q_{n, c c}^{-1}+2 s \lambda_{n}\left[a_{n}\left(s x_{n}\right)-\left(s x_{n}\right)^{-1}-s \lambda_{n}\right] \\
& -2 \lambda_{n} d_{n}^{2}\left[a_{n}\left(x_{n}\right)-x_{n}^{-1}-\lambda_{n}\right], \\
q_{n, c s}^{-1}= & q_{n, c c}^{-1}+2 s \lambda_{n}\left[a_{n}\left(s x_{n}\right)-\left(s x_{n}\right)^{-1}-s \lambda_{n}\right], \\
q_{n, s c}^{-1}= & q_{n, c c}^{-1}-2 \lambda_{n} d_{n}^{2}\left[a_{n}\left(x_{n}\right)-x_{n}^{-1}-\lambda_{n}\right], \\
q_{n, c c}^{-1}= & 1-d_{n}^{2},
\end{aligned}
$$

is the $n$-th normalization factor,

$$
\begin{aligned}
& \psi_{n, s s}(x)=\psi_{n, c c}(x)-\frac{\lambda_{n}}{\delta_{n}} \frac{s J_{0}(s \beta x)-d_{n} J_{0}(\beta x)}{\delta_{n}^{2}+x^{2}}, \\
& \psi_{n, c s}(x)=\psi_{n, c c}(x)-\frac{\lambda_{n}}{\delta_{n}} \frac{s J_{0}(s \beta x)}{\delta_{n}^{2}+x^{2}} \\
& \psi_{n, s c}(x)=\psi_{n, c c}(x)+\frac{\lambda_{n}}{\delta_{n}} \frac{d_{n} J_{0}(\beta x)}{\delta_{n}^{2}+x^{2}}
\end{aligned}
$$

$$
\begin{aligned}
\psi_{n, c c}(x)= & \frac{\delta_{n} a_{n}\left(s x_{n}\right) J_{0}(s \beta x)-x J_{1}(s \beta x)}{\delta_{n}^{4}-x^{4}} \\
& -\frac{d_{n}\left[\delta_{n} a_{n}\left(x_{n}\right) J_{0}(\beta x)-x J_{1}(\beta x)\right]}{\delta_{n}^{4}-x^{4}},
\end{aligned}
$$

is the $n$-th eigenfunction of the vibrating plate, $a_{n}\left(x_{n}\right)=G_{1}\left(x_{n}\right) / G_{0}\left(x_{n}\right), a_{n}\left(s x_{n}\right)=G_{1}\left(s x_{n}\right) / G_{0}\left(s x_{n}\right), d_{n}=$ $G_{0}\left(x_{n}\right) / s G_{0}\left(s x_{n}\right), \beta=k a, G_{\mu}(x)=J_{\mu}(x)-C_{n} N_{\mu}(x)$ for $\mu \in\{0,1\}$ and $x \in\left\{x_{n}, s x_{n}\right\}$. The integration in equation (11) is performed in the plane of complex variable along the real axis. The integrals, computed within the intervals $(0,1)$ and $(1, \infty)$, represent the active and reactive self-impedance, respectively. Integral (11) and its integration path are analogous with those valid for a clamped annular plate (cf. Rdzanek and Engel 2000).

\section{ASYMPTOTICS FOR THE HIGH FREQUENCIES}

It does not seem possible to formulate the self-impedance directly from equation (11). Nevertheless, it is possible to find some asymptotic expressions for the active and reactive selfimpedance valid within the high frequency range. The active self-impedance was found using a specially selected integral, computed in the plane of complex variable along a closed path. The asymptotic method of stationary phase was used while computing the integrals over the infinite intervals.

After an amount of the mathematical manipulation some asymptotic formulations for the active and reactive selfimpedance for the simply supported-clamped annular plates were found. The whole computing procedure had been presented in detail earlier for a clamped annular plate (cf. Rdzanek and Engel 2000), and therefore only the asymptotic results obtained have been presented in this paper. During computing the active and reactive self-impedance it was possible to separate their non-oscillating and oscillating parts, denoted with a bar or with a tilde, respectively. The active self-impedance is presented as

$$
\Pi_{a n}=\bar{\Pi}_{a n}+\tilde{\Pi}_{a n}+O\left(\delta_{n}^{4} \beta^{-3 / 2}\right),
$$

where the term covering symbol $O$ denotes the approximation error. 
The non-oscillating and oscillating parts of the active self-impedance can be formulated as

$$
\begin{aligned}
\bar{\Pi}_{a n}= & \frac{1}{\sqrt{1+\delta_{n}^{2}}}+\frac{q_{n} u_{n}}{2}\left(\frac{1}{\sqrt{1-\delta_{n}^{2}}}-\frac{1}{\sqrt{1+\delta_{n}^{2}}}\right) \\
\tilde{\Pi}_{a n}= & \frac{2 q_{n}}{\beta \sqrt{\pi \beta}} \frac{\delta_{n}^{4}}{\left(1+\delta_{n}^{2}\right)^{2}}\left\{\left(b_{0}^{2}-b_{1}^{2}\right) \cos w_{1}\right. \\
& +2 b_{0} b_{1} \sin w_{1} \\
& +\frac{1}{s \sqrt{s}}\left[\left(h_{0}^{2}-h_{1}^{2}\right) \cos w_{2}+2 h_{0} h_{1} \sin w_{2}\right] \\
& -\frac{2 \sqrt{2}}{\sqrt{s} \sqrt{s-1}}\left[\varepsilon\left(h_{1} b_{0}-h_{0} b_{1}\right) \cos w_{3}\right. \\
& \left.+\left(h_{1} b_{1}+h_{0} b_{0}\right) \sin w_{3}\right] \\
& +\frac{2 \sqrt{2}}{\sqrt{s} \sqrt{s+1}}\left[\left(h_{1} b_{1}-h_{0} b_{0}\right) \cos w_{4}\right. \\
- & \left.\left.\left(h_{1} b_{0}+h_{0} b_{1}\right) \sin w_{4}\right]\right\}
\end{aligned}
$$

where $w_{1}=2 \beta+\pi / 4, w_{2}=2 s \beta+\pi / 4, w_{3}=(s-1) \beta+\pi / 4$, $w_{4}=(s+1) \beta+\pi / 4$ and

$$
\varepsilon= \begin{cases}1, & \text { for ss plate } \\ -1, & \text { for cs and sc plates }\end{cases}
$$

$$
\begin{aligned}
& u_{n, s s}=u_{n, c c}-2 \lambda_{n} x_{n}^{-1}\left(1-d_{n}^{2}\right), \\
& u_{n, c s}=u_{n, c c}-2 \lambda_{n} x_{n}^{-1}, \\
& u_{n, s c}=u_{n, c c}+2 \lambda_{n} x_{n}^{-1} d_{n}^{2}, \\
& u_{n, c c}=1+a_{n}^{2}\left(s x_{n}\right)-d_{n}^{2}\left[1+a_{n}^{2}\left(x_{n}\right)\right], \\
& h_{0}=1 /\left(1-\delta_{n}^{2}\right), b_{0}=d_{n} h_{0},
\end{aligned}
$$$$
h_{1,(s s, c s)}=\delta_{n} a_{n}\left(s x_{n}\right) h_{0}+s \lambda_{n} / \delta_{n},
$$$$
h_{1, s c}=\delta_{n} a_{n}\left(s x_{n}\right) h_{0},
$$$$
b_{1,(s s, s c)}=d_{n}\left[\delta_{n} a_{n}\left(x_{n}\right) h_{0}+\lambda_{n} / \delta_{n}\right] \text {, }
$$$$
b_{1, c s}=d_{n} \delta_{n} a_{n}\left(x_{n}\right) h_{0} .
$$

The reactive self-impedance is presented as

$$
\Pi_{r n}=\bar{\Pi}_{r n}+\tilde{\Pi}_{r n}+O\left(\delta_{n}^{4} \beta^{-3 / 2}\right),
$$

with the analogy approximation error as in equation (20). The non-oscillating and oscillating parts of the reactive selfimpedance can be formulated as follows:

$$
\begin{array}{r}
\bar{\Pi}_{r n}=\frac{q_{n}}{\pi s \beta}\left[\frac{\alpha_{1 n}}{1+\delta_{n}^{2}}+\frac{\alpha_{2 n} \arcsin \delta_{n}}{2 \delta_{n} \sqrt{1-\delta_{n}^{2}}}+\right. \\
\left.+\frac{\alpha_{3 n} \operatorname{arcsinh} \delta_{n}}{2 \delta_{n}\left(1+\delta_{n}^{2}\right)^{3 / 2}}\right]
\end{array}
$$

$$
\begin{aligned}
& \tilde{\Pi}_{r n}= \frac{2 q_{n}}{\beta \sqrt{\pi \beta}} \frac{\delta_{n}^{4}}{\left(1+\delta_{n}^{2}\right)^{2}}\left\{\left(b_{1}^{2}-b_{0}^{2}\right) \sin w_{1}\right. \\
&+2 b_{1} b_{0} \cos w_{1} \\
&+\frac{1}{s \sqrt{s}}\left[\left(h_{1}^{2}-h_{0}^{2}\right) \sin w_{2}+2 h_{1} h_{0} \cos w_{2}\right] \\
&-\frac{2 \sqrt{2}}{\sqrt{s} \sqrt{s-1}}\left[\left(h_{1} b_{0}-h_{0} b_{1}\right) \sin w_{3}\right. \\
&\left.\quad+\left(h_{1} b_{1}+h_{0} b_{0}\right) \cos w_{3}\right] \\
&-\frac{2 \sqrt{2}}{\sqrt{s} \sqrt{s+1}}\left[\left(h_{1} b_{1}-h_{0} b_{0}\right) \sin w_{4}\right. \\
&\left.\left.\quad+\left(h_{1} b_{0}+h_{0} b_{1}\right) \cos w_{4}\right]\right\}
\end{aligned}
$$

where all the denotations used are analogous with those used to formulate the active self-impedance, with the exception of the following factors

$$
\begin{aligned}
& \alpha_{1 n, s s}=\alpha_{1 n, c c}+2 s \lambda_{n}\left\{a_{n}\left(s x_{n}\right)-s \lambda_{n}\right. \\
& \left.+d_{n}^{2}\left[a_{n}\left(x_{n}\right)-\lambda_{n}\right]\right\} \text {, } \\
& \alpha_{1 n, c s}=\alpha_{1 n, c c}+2 s \lambda_{n}\left[a_{n}\left(s x_{n}\right)-s \lambda_{n}\right] \text {, } \\
& \alpha_{1 n, s c}=\alpha_{1 n, c c}+2 s d_{n}^{2} \lambda_{n}\left[a_{n}\left(x_{n}\right)-\lambda_{n}\right] \text {, } \\
& \alpha_{1 n, c c}=\left\{1+\delta_{n}^{2} a_{n}^{2}\left(s x_{n}\right)+s d_{n}^{2}\left[1+\delta_{n}^{2} a_{n}^{2}\left(x_{n}\right)\right]\right\} h_{0}, \\
& \alpha_{2 n, s s}=\alpha_{2 n, c c}+4 s \lambda_{n}\left[a_{n}\left(s x_{n}\right)+d_{n}^{2} a_{n}\left(x_{n}\right)\right] \text {, } \\
& \alpha_{2 n, c s}=\alpha_{2 n, c c}+4 s \lambda_{n} a_{n}\left(s x_{n}\right) \text {, } \\
& \alpha_{2 n, s c}=\alpha_{2 n, c c}+4 s d_{n}^{2} \lambda_{n} a_{n}\left(x_{n}\right) \text {, } \\
& \alpha_{2 n, c c}=\left\{-\left(3-4 \delta_{n}^{2}\right)\left[a_{n}^{2}\left(s x_{n}\right)+s d_{n}^{2} a_{n}^{2}\left(x_{n}\right)\right]\right. \\
& \left.-\left(1-2 \delta_{n}^{2}\right)\left(1+s d_{n}^{2}\right)\right\} h_{0}, \\
& \alpha_{3 n, s s}=\alpha_{3 n, c c}-4 s \lambda_{n}\left\{( 2 + 3 \delta _ { n } ^ { 2 } ) \left[a_{n}\left(s x_{n}\right)\right.\right. \\
& \left.\left.+d_{n}^{2} a_{n}\left(x_{n}\right)\right]-\lambda_{n}\left(1+2 \delta_{n}^{2}\right)\left(s+d_{n}^{2}\right)\right\}, \\
& \alpha_{3 n, c s}=\alpha_{3 n, c c}-4 s \lambda_{n}\left[\left(2+3 \delta_{n}^{2}\right) a_{n}\left(s x_{n}\right)\right. \\
& \left.-s \lambda_{n}\left(1+2 \delta_{n}^{2}\right)\right] \text {, } \\
& \alpha_{3 n, s c}=\alpha_{3 n, c c}-4 s d_{n}^{2} \lambda_{n}\left[\left(2+3 \delta_{n}^{2}\right) a_{n}\left(x_{n}\right)\right. \\
& \left.-\lambda_{n}\left(1+2 \delta_{n}^{2}\right)\right] \text {, } \\
& \alpha_{3 n, c c}=\left(3+4 \delta_{n}^{2}\right)\left[a_{n}^{2}\left(s x_{n}\right)+s d_{n}^{2} a_{n}^{2}\left(x_{n}\right)\right] \\
& -\left(1+2 \delta_{n}^{2}\right)\left(1+s d_{n}^{2}\right) .
\end{aligned}
$$

The results obtained and presented in their elementary forms (20) and (29) are valid for frequencies higher than successive eigenfrequencies of the plate, i.e. for $k>k_{n}$. The results cover an approximation error, which theoretical estimation is $\delta_{n}^{4} / \beta^{3 / 2}$. The value of the error is small for $k>k_{n}$ and decreases considerably with an increase in the plate's vibration frequency. The elementary formulations can be used if the following conditions are satisfied: the free field conditions, when the plate is embedded in an infinite baffle, and when the plate's excitation is axisymmetric and time-harmonic. 

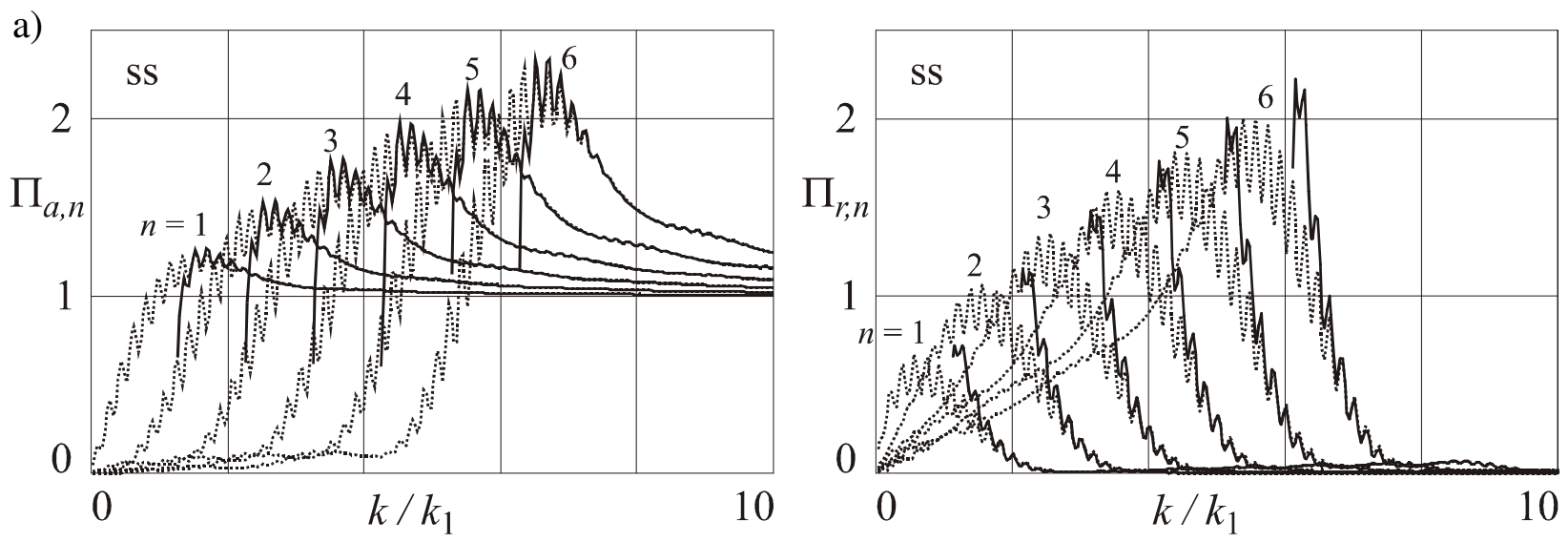

b)
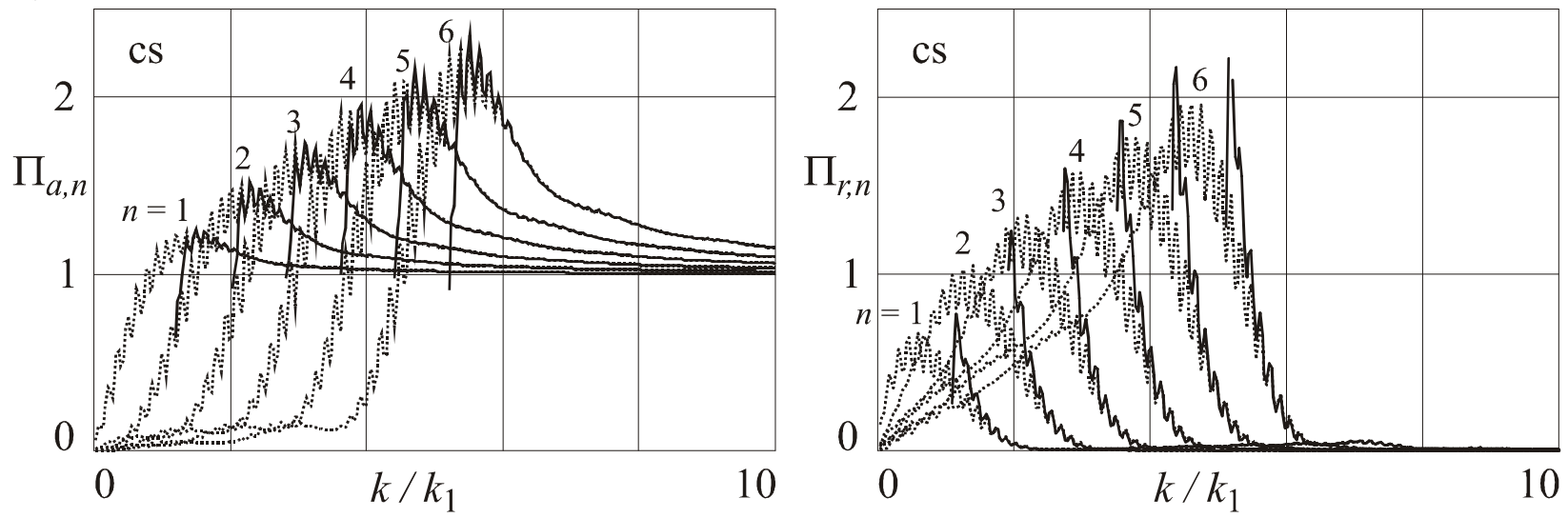

c)
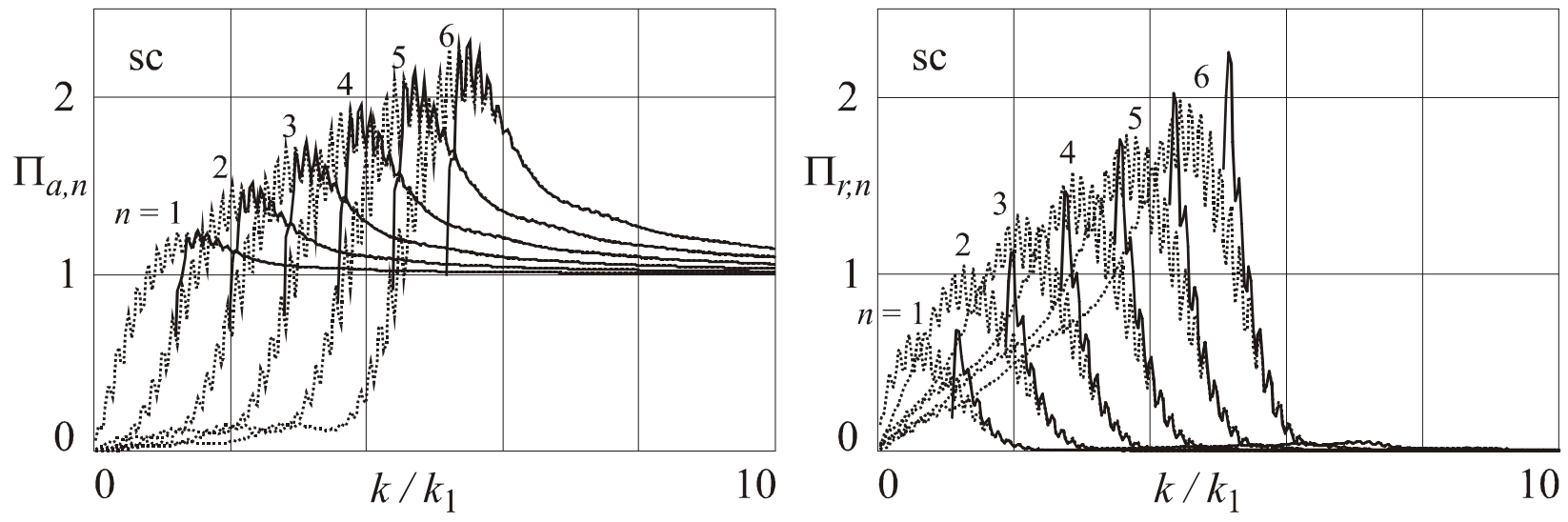

Fig. 1. The normalized active and reactive self-impedance $\Pi_{a, n}$ and $\Pi_{r, n}$, respectively, for $b / a=1.2$ and for three different annular plates with one edge simply supported and the other clamped or also simply supported. All the dotted curves in this figure are obtained from the integral formula (11), and all the solid curves from the asymptotic formulae (20) and (29),

boundary configurations: a) ss, b) cs, c) sc 

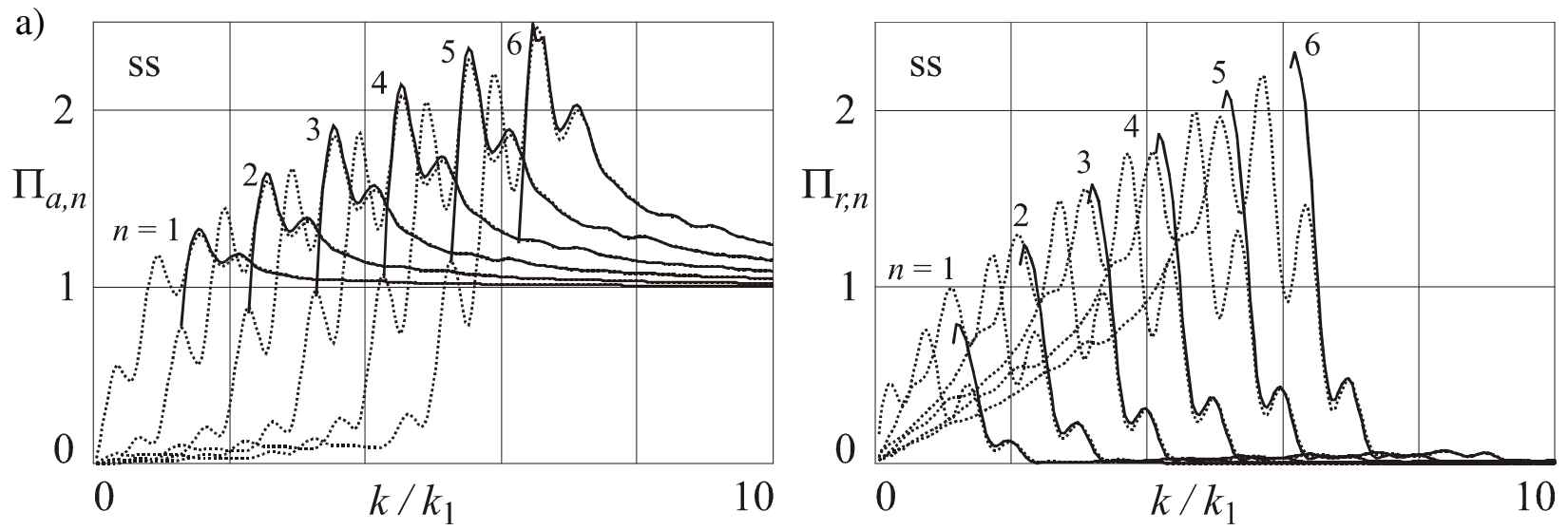

b)
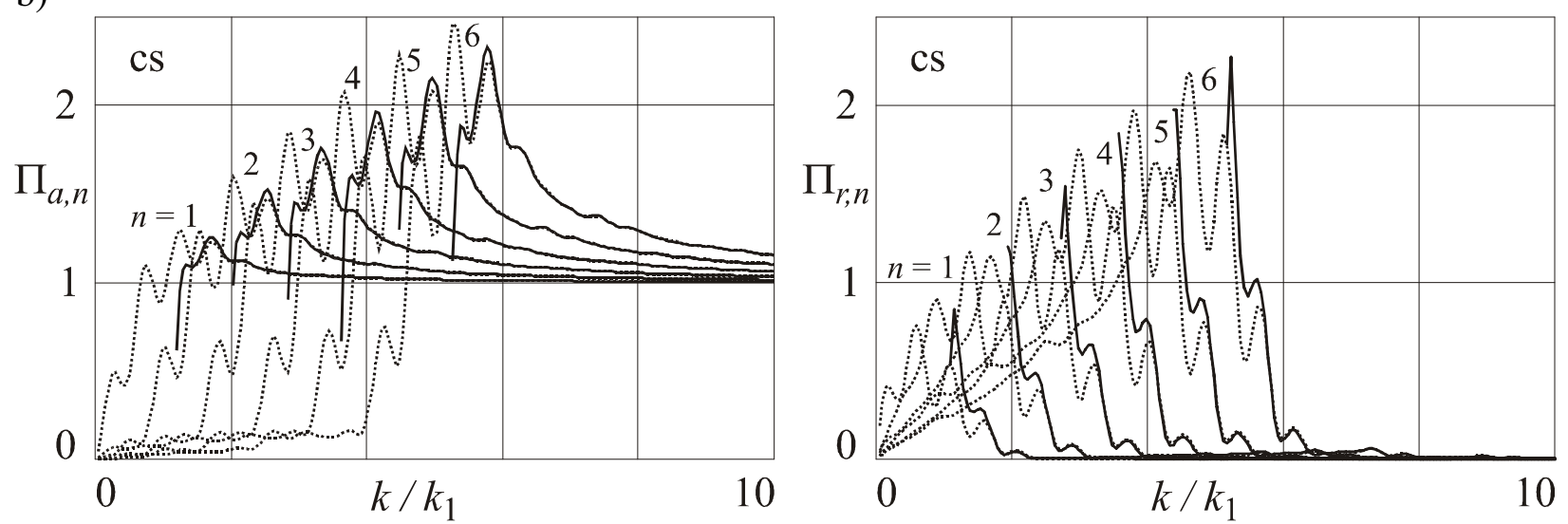

c)
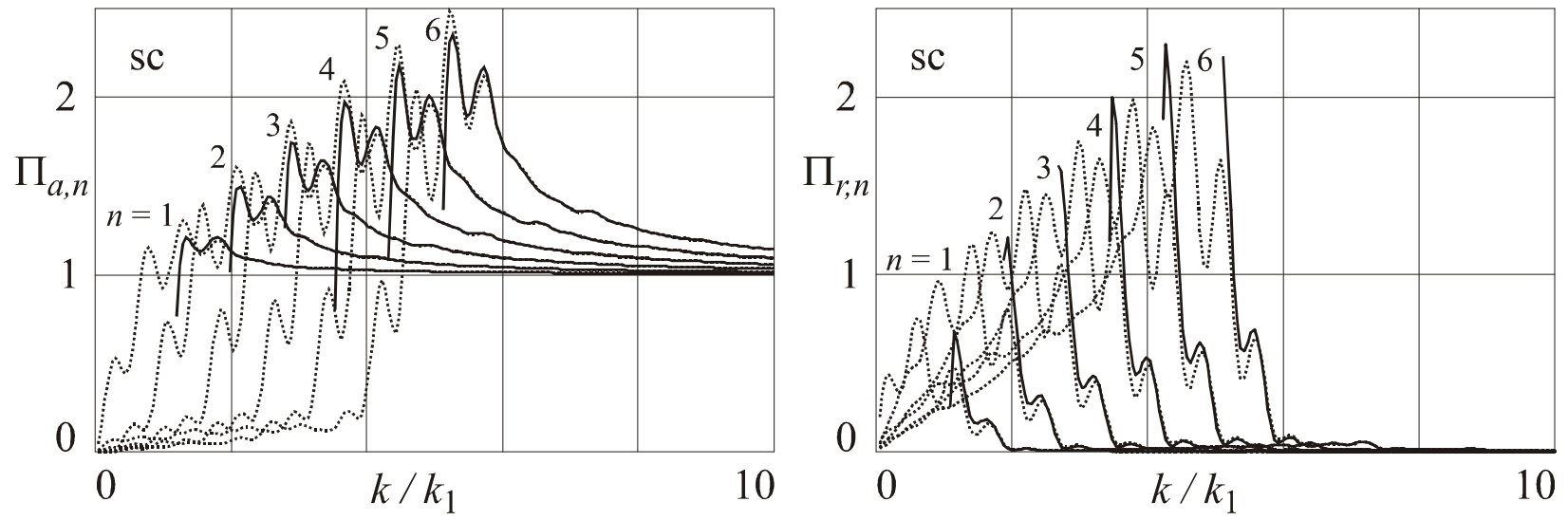

Fig. 2. The normalized active and reactive self-impedance $\Pi_{a, n}$ and $\Pi_{r, n}$, respectively, for $b / a=2.0$ and for three different annular plates with one edge simply supported and the other clamped or also simply supported. All the dotted curves in this figure are obtained from the integral formula (11), and all the solid curves from the asymptotic formulae (20) and (29),

boundary configurations: a) ss, b) cs, c) sc 

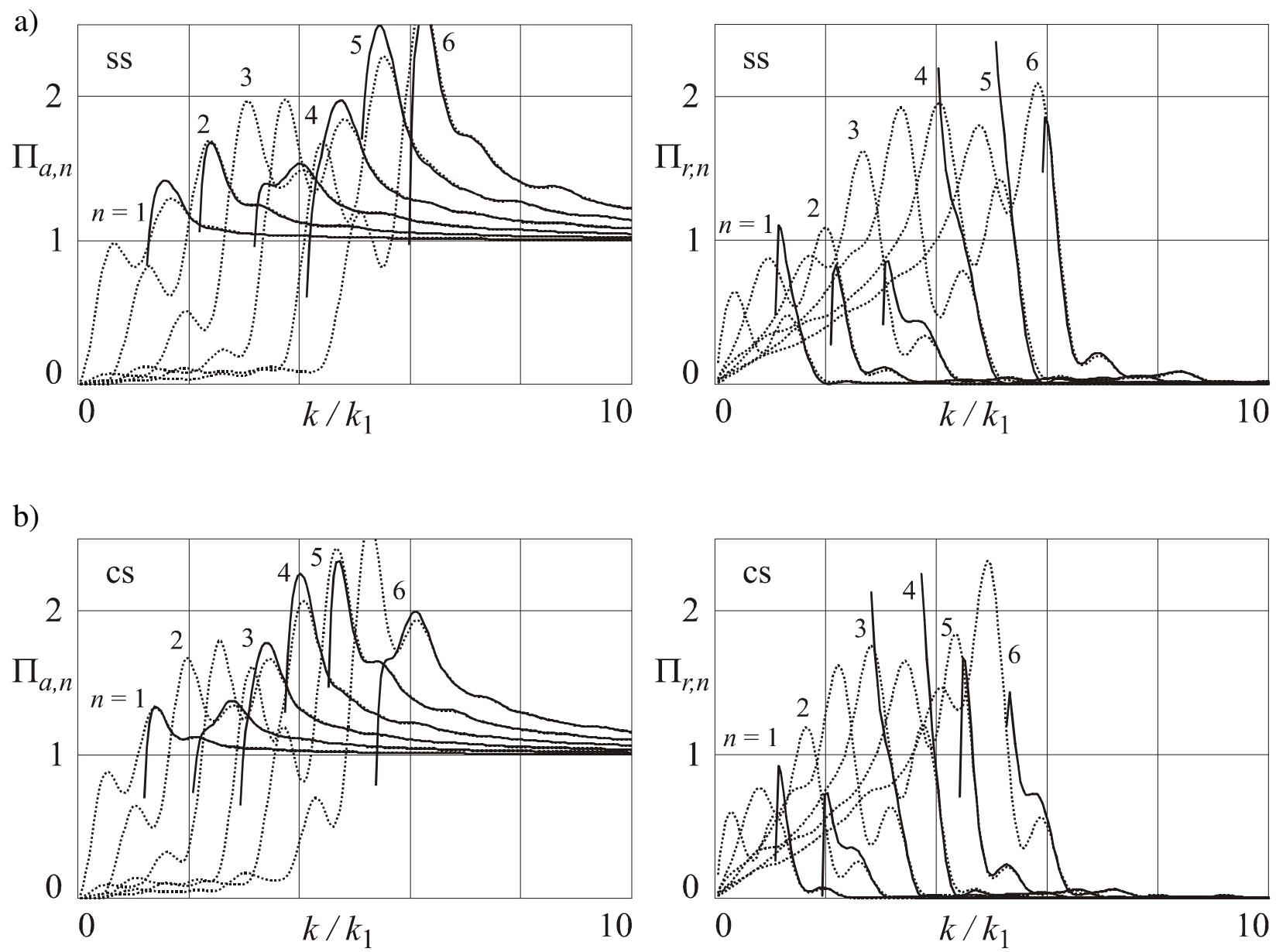

c)
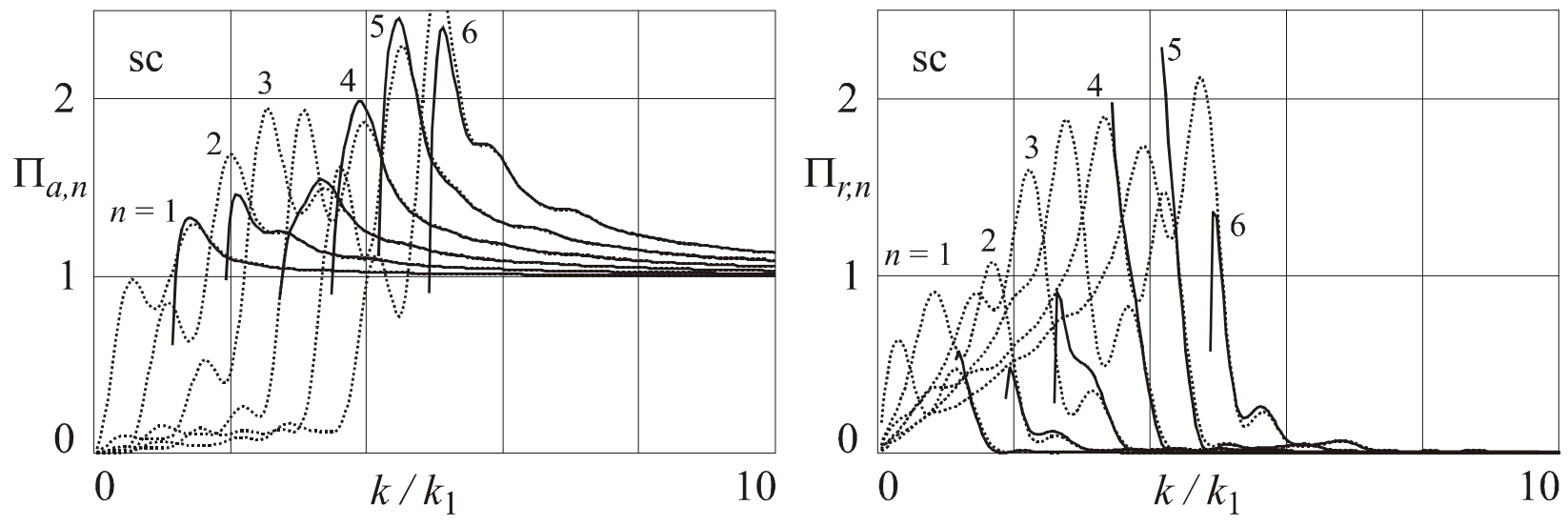

Fig. 3. The normalized active and reactive self-impedance $\Pi_{a, n}$ and $\Pi_{r, n}$, respectively, for $b / a=5.0$ and for three different annular plates with one edge simply supported and the other clamped or also simply supported. All the dotted curves in this figure are obtained from the integral formula (11), and all the solid curves from the asymptotic formulae (20) and (29),

boundary configurations: a) ss, b) cs, c) sc 
a)

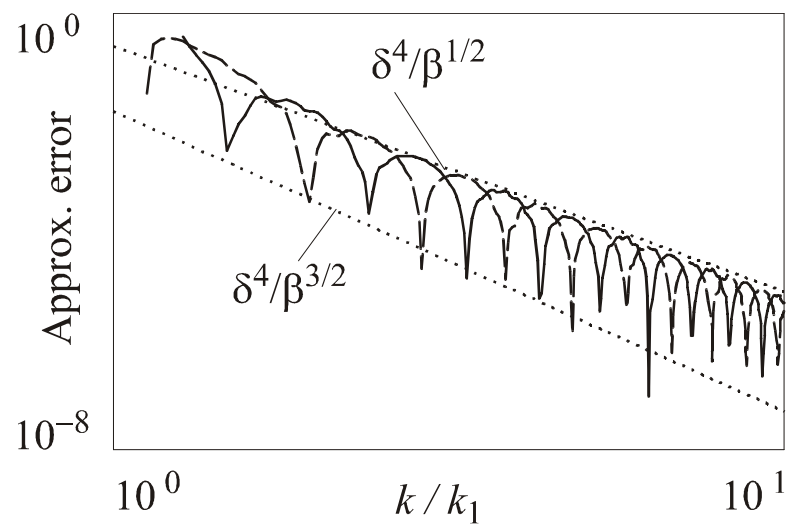

b)

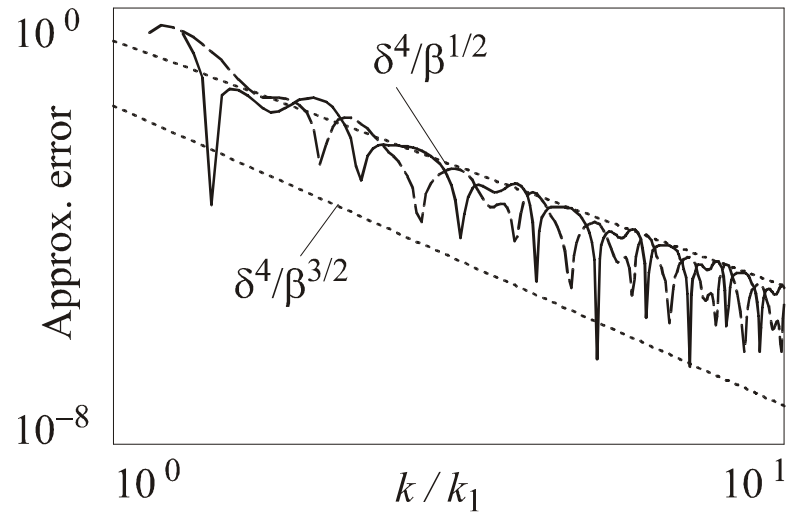

c)

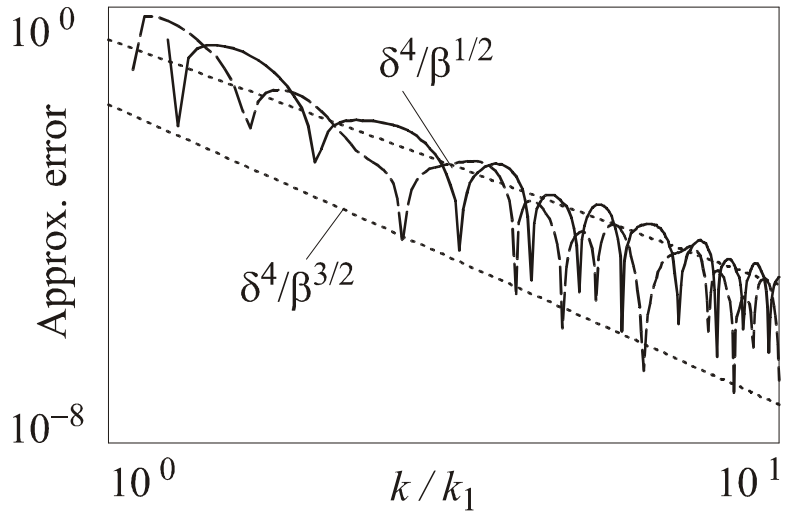

Fig. 4. The approximation error order estimated as $\left|\Pi_{I}-\Pi_{A}\right|$, where $\Pi_{I}$ and $\Pi_{A}$ is the self-impedance of the first elastic body mode computed from the integral formulae and asymptotic formulae, respectively, and the theoretical value of the approximation error order taken as $\delta_{n}^{4} / \beta^{3 / 2}$ or $\delta_{n}^{4} / \beta^{1 / 2}$. The theoretical curves are plotted with dotted lines, and the estimated curves are plotted with solid and dashed lines, for the active and reactive self-impedance, respectively, for the three boundary configurations: a) ss; b) cs; c) sc 


\section{NUMERICAL ANALYSIS}

Several curves representing the active and reactive selfimpedance of the plate are plotted in figures 1-3. They are valid for the three boundary configurations discussed, for three sample values of the plate's geometric parameter $s$, and for the six of the lowest elastic body modes of the plate. All the curves are plotted in terms of the acoustic wavelength $k$ normalized by the structural wavelength $k_{1}$ associated with the first elastic body mode. Generally, there is rather small influence of the boundary configuration on the shape of the self-impedance curves for small values of $s$ (cf. fig. 1). The influence is greater for the higher values of parameter $s$ (cf. figs. 2-3). The curves representing the normalized active and reactive self-impedance of a simply supported annular plate approach their values of 1 and 0 , respectively, at a slower rate than for both remaining boundary configurations. Any detailed analysis of the influence of the self-impedance on the total sound power radiated has not been discussed in this paper. Figures 1-3 show that a change in the boundary configuration of even one edge of an annular plate can cause a considerable change in its self-impedance, and therefore all the differences in the corresponding formulations should be taken into account.

Some curves representing different estimations of the approximation error of the active and reactive self-impedance of the first elastic body mode are plotted in figure 4. One of the estimations was found by comparing the results obtained from asymptotic and integral formulae. The estimated values are slightly greater than those determined theoretically for $\delta_{n}^{4} / \beta^{3 / 2}$ for all the boundary configurations considered. However, the regular value of the approximation error does not exceed the value of $\delta_{n}^{4} / \beta^{1 / 2}$ (cf. fig. 4).

\section{CONCLUDING REMARKS}

Some elementary formulations for the normalized active and reactive self-impedance of an annular plate with one edge simply supported and the other one clamped or also simply supported have been presented. Those formulations are easy to express in terms of some computer code and they do not need much processor capacity. They are valid within the range of high frequencies. Therefore, the formulations together with some formulations valid within the remaining frequency range can be useful for some engineering applications as well as for some further theoretical analysis of the total sound power radiated by an axisymmetrically excited plate in an acoustic fluid.

\section{ACKNOWLEDGMENTS}

The authors would like to express their sincere gratitude to Prof. Zbigniew Engel, the world-renowned scientist and professor in the field of vibroacoustics, for the inspiration and encouragement to solve the problems presented in this paper as well as in many others. The research presented in this paper was partially supported under The Centre for Innovation and Transfer of Natural Sciences and Engineering Knowledge Project at The University of Rzeszów.

\section{References}

Anderson J.S., Bratos-Anderson M., 2005, Radiation efficiency of rectangular orthotropic plates. Acta Acustica united with Acustica, 91(1), 61-76.

Arenas J.P., Albarracín C., 2007, Estimation of the active and reactive sound power using hyper-matrices of impedance. [in:] 14th International Congress on Sound and Vibration 2007, ICSV 2007, vol. 3, 2705-2712.

Arenas J.P., Ramis J., Alba J., 2010, Estimation of the sound pressure field of a baffled uniform elliptically shaped transducer. Applied Acoustics, 71(2), 128-133. doi: 10.1016/j.apacoust.2009.08.003.

Brański A., Szela S., 2011, Evaluation of the active plate vibration reduction by the parameter of the acoustic field. Acta Physica Polonica A, 119(6A), 942-945.

Czarnecki S., Engel Z., Panuszka R., 1981, Sound power and radiation efficiency of a circular plate. Archives of Acoustics, 16(4), 339-357.

Kozień M.S., Wiciak J., 2010, Passive structural acoustic control of the smart plate - FEM simulation. Acta Physica Polonica A, 118(6), 1186-1188, http://przyrbwn.icm.edu.pl/APP/PDF/118/a118z6p25.pdf.

Kuo D., Shiah Y.C., Huang J.H., 2011, Modal analysis of a loudspeaker and its associated acoustic pressure field. J. Vib. Acoust., 133(3), 031015 (11 pages). doi: 10.1115/1.4003268.

Lee H., Singh R., 2005, Acoustic radiation from out-of-plane modes of an annular disk using thin and thick plate theories. Journal of Sound and Vibration, 282, 313-339. doi: 10.1016/j.jsv.2004.02.059.

Lee M.-R., Singh R., 1994, Analytical formulations for annular disk sound radiation using structural modes. Journal of the Acoustical Society of America, 95(6), 3311-3323. doi: 10.1121/1.409993.

Leissa A.W., 1969, Vibration of Plates, vol. SP-160. NASA, Washington, D.C. U.S. Government Printing Office.

Leniowska L., 2008, Influence of damping and fluid loading on the plate vibration control. Archives of Acoustics, 33(4), 531-540.

Mazur K., Pawełczyk M., 2013, Active noise control with a single nonlinear control filter for a vibrating plate with multiple actuators. Archives of Acoustics, 38(4), 537-545. doi: 10.2478/aoa-2013-0063.

McLachlan N.W., 1955, Bessel functions for engineers. Clarendon Press, Oxford.

Mellow T., Kärkkäinen L., 2007, On the sound field of a shallow spherical shell in an infinite baffle. Journal of the Acoustical Society of America, 121(6), 3527-3541. doi: 10.1121/1.2715464.

Oberst S., Lai J.C.S., Marburg S., 2013, Guidelines for numerical vibration and acoustic analysis of disc brake squeal using simple models of brake systems. Journal of Sound and Vibration, 332(9), 2284-2299. doi: 10.1016/j.jsv.2012.11.034.

Rdzanek W.P., 2003, The sound power of an individual mode of a clamped-free annular plate. Journal of Sound and Vibration, 261, 775-790. doi: 10.1016/S0022-460X(02)00984-7.

Rdzanek W.P., Engel Z., 2000, Asymptotic formulas for the acoustic power output of a clamped annular plate. Applied Acoustics, 60(1), 29-43. doi: 10.1016/S0003-682X(99)00041-9.

Rdzanek W.P., Rdzanek W.J., 2007, Asymptotic formulas for the acoustic radiation impedance of an elastically supported annular plate. Journal of Sound and Vibration, 301(3-5), 544-559. doi: $10.1016 /$ j.jsv.2006.10.031.

Szemela K., 2013, High frequency approximation for the modal acoustic impedance coefficients of a circular plate located at the boundary of the three-wall corner region. Journal of Computational Acoustics, 21(4), pp. 1350016. doi: 10.1142/S0218396X13500161.

Wrona S., Pawełczyk M., 2013, Controllability-oriented placement of actuators for active noise-vibration control of rectangular plates using a memetic algorithm. Archives of Acoustics, 38(4), 529-536. doi: 10.2478/aoa-2013-0062.

Zawieska W.M., 2007, A power transformer as a source of noise. International Journal of Occupational Safety and Ergonomics, 13(4), 381-389. http://www.ciop.pl/24379.

Zhou R., Crocker M.J., 2010, Sound transmission characteristics of asymmetric sandwich panels. Journal of Vibration and Acoustics. Transactions of the ASME, 132(3), 0310121-0310127. doi: 10.1115/1.4000786. 